\title{
LOS CONSELLS COMARCALS. UN ESTUDIO DE CASO: LA COMARCA DEL BAIX LLOBREGAT
}

\author{
POR \\ Román Castro Alcaide*
}

\begin{abstract}
SUMARio: 1. La organización territorial en Cataluña.-2. La comarca: 2.1 Competencias y financiación comarcal.-2.1.1 Las competencias comarcales. 2.1.2 La financiación comarcal.-3. El Consell ComarCaL del BaIX LlobreGAT: 3.1 El Reglamento orgánico.-3.2 Los órganos de gobierno.-4. EL Consell Comarcal del Baix llobregat: una nueva administración local: 4.1 Los primeros traspasos competenciales.-5. BALANCE: DOS AÑOS DE ACTUACIÓN.-6. A MODO DE CONCLUSIÓN
\end{abstract}

\section{LA ORGANIZACION TERRITORIAL EN CATALUÑA}

El Estatuto de Autonomía de Cataluña, en su artículo quinto, indica de forma clara y concisa que "La Generalitat de Cataluña estructurará su organización territorial en municipios y comarcas; también podrá crear demarcaciones supracomarcales».

El gobierno autónomo puso ya en cuestión desde sus inicios el papel de las provincias. Las provincias fueron para gran parte del catalanismo político un brazo administrativo de la organización central del Estado. Tradicionalmente cuestionado por ser desde su creación, a mediados del siglo XIX un tentáculo político y administrativo del mismo (1).

Diversos autores han manifestado su opinión en torno a la comarca como ente territorial. En esta línea encontramos algunos que, aun preconizando la legitimidad para dar vía jurídica y administrativa a los entes comarcales, opinan que esto no ha de ser a costa de la organización provincial (2). Por otra parte, otros autores, donde se engloban la mayoría de los políticos catalanes contempo-

- Licenciado en Ciencias Políticas y Sociología por la Universidad Autónoma de Barcelona y Diplomado en Ciencias Sociales por la Escuela Superior de Ciencias Sociales de Barcelona. (ICESB).

(1) El tema de las relaciones entre Administraciones autónomas y Administración provincial no es nuevo. Siempre que se ha aprobado una Constitución el tema de la provincia ha quedado en entredicho. El proyecto de Constitución Federal de 1873 (inspirado en buena parte por federalistas catalanes) permitia a los Estados competencias para establecer su propia organización territorial. La exposición de motivos indicaba que «... señalamos como nuevos Estados de la República los antiguos Reinos de la Monarquía y dejamos que los Estados conserven, si quieren, las provincias o regulen a su arbitrio la más conveniente y sabia división territorial»).

(2) En este sentido, LUIS MORELL opina que "En el interior de los marcos provinciales y contemplando cada territorio provincial, la organización administrativa de las Comunidades Autónomas tiene que incorporar de algún modo la idea de comarca. Ciertamente, en favor de estos espacios infraprovinciales está un criterio de resurrección de unidades históricas venidas 
ráneos, aducen la defensa de las comarcas a costa de la supresión de la división provincial establecida por Decreto de la Reina Gobernadora el 30 de noviembre de 1833 (3).

En cualquier caso parece ser que los defensores de la organización comarcal, lo son, en tanto en cuanto que entiende el nivel comarcal como marco idóneo para el desarrollo y acercamiento de servicios de distinta índole al ciudadano. Como por ejemplo los derivados para la mejora de infraestructuras territoriales, fomento y orientación de producciones agrícolas, promoción de zonas industriales, asistencia social o servicios sanitarios de cierta envergadura.

En el proceso de redefinición del mapa administrativo catalán incluyen diferentes legislaciones tendentes a reformular y estructurar un nuevo radelo de administración pública en Cataluña.

La Ley 5/1987, de 4 de abril, del Régimen Provisional de las Competencias de las Diputaciones Provinciales, es uno de los primeros intentos más importantes donde se cristaliza el rechazo a la provincias (4). Dicha Ley propugna el objeto de regular las competencias de las Diputaciones Provinciales. En su artículo 1 el legislador ya indica el objetivo de hacer desaparecer las provincias,

abajo con la institucionalización a principio del siglo $\mathrm{XIX}$ de una configuración distinta de territorio, como una constante del Derecho comparado en la medida en que las comarcas, en primer lugar, constituyen un espacio capaz de superar las limitaciones de los pequeños municipios que constituyen el componente general del régimen local en Europa, y concretamente en España... el tema de la comarca se ha venido suscitando en las últimas décadas como correctivo ideal de las limitaciones de los municipios pequeños para ser una eficaz organización prestadora de servicios públicos... en Comunidades Autónomas como la de Cataluña o País Vasco, la comarca no va a representar otra cosa que romper una solución de continuidad con instituciones locales que llegan hasta los comienzos del siglo XIX"). Véase LUIS MORELL OCAÑA "La provincia en la configuración y ordenación territorial de las Comunidades Autónomas" (fragmento de la Ponencia leída en las Primeras Jornadas de Estudios Extremeños. Badajoz, noviembre de 1981). Revista Española de Derecho Administrativo, núm. 31, pp. 613 y ss. Diciembre 1981.

(3) MACIȦ ALAVEDRA exconseller de Governació de la Generalitat de Catalunya, en la introducción de una conferencia sobre la comarca como ente territorial, afirmaba que «la creació de la comarca dins l'organització territorial catalana no ha de ser un element que incrementi irreflexivament els nivells de l'esmentada organització administrativa, sinó ans al contrari ha de ser un ens amb vocació de simplificació, de dinamicitat i de millorament i d'apropament dels serveis al seu destinatari, i de suport de l'acció municipal o de superació de les seves insuficiències, responent aixi a les exigències de la societat i d'una administració moderna». Prólogo de las conferencias celebradas en la Escola d’Administració Pública de Catalunya "La Comarca com a ens territorial» Generalitat de Catalunya. Escola d'Administració Pública de Catalunya, 1984

(4) Es preciso recordar que el primer intento para alterar el mapa local autonómico, fue la aprobación por parte del Parlamento Autónomo de la Ley 6/1980, de 17 de diciembre, de Transferencia Urgente y Plena de las Diputaciones a la Generalitat. Ley que tras la sentencia del Tribunal Constitucional núm. 40/1981, de 28 de julio, quedó totalmente desvirtuada al estimar este alto Tribunal el recurso de insconstitucionalidad interpuesto por los Abogados del Estado a propuesta del Presidente de Gobierno. Dicha sentencia declaró inconstitucionales los artículos $1,2,3,5$ y 9 y la disposición transitoria primera y disposición final segunda de la mencionada Ley. 
«Esta Ley tiene por objeto regular el régimen provisional de las competencias de las Diputaciones Provinciales catalanas $y$ el ejercicio de estas competencias, mientras no se produzcan las condiciones legales que hagan posible que el gobierno y la administración de las provincias se integran en la Generalitat, con la consecuente desaparición de la división de Cataluña en provincias». El objetivo final, tal y como se indica en la disposición adicional primera, es obtener a través de la alteración de los límites provinciales una única provincia, llamada Cataluña.

El mismo día en que se aprobó la Ley 5/1987, también se hizo lo propio con la Ley 6/1987, sobre la organización comarcal de Cataluña, y la Ley 7/1987, sobre actuaciones públicas especiales en la conurbación de Barcelona. La Ley 8/1987, de 15 de abril, Municipal y de Régimen Local de Cataluña, sería la cuarta que en el espacio de quince días configuró, junto con las tres restantes anteriormente comentadas, la organización territorial de Cataluña. La Ley Municipal de Régimen Local dictada en el marco de las bases estatales (Ley Reguladora de Bases del Régimen Local), regulaba el régimen jurídico de las administraciones locales catalanas. Punto de referencia ordinario para determinar el régimen local vigente en Cataluña.

La aprobación de la Ley 7/1987 por la cual se establecen y regulan las actuaciones públicas especiales en la conurbación de Barcelona y en las comarcas comprendidas dentro de su influencia directa, tenía como principal objetivo la remodelación del área metropolitana de Barcelona. El mayor fundamento político de este hecho, independientemente de tender a un nuevo marco administrativo catalán, era limitar la proyección institucional de Barcelona. En este sentido y según la disposición final segunda de dicha Ley, se deroga el Decreto-ley 5/1974, de 24 de agosto, que creaba la Entidad Municipal Metropolitana de Barcelona. Se crean a la vez dos nuevas entidades metropolitanas a las que se asignan una parte de los recursos y competencias de la extinguida Corporación Metropolitana de Barcelona (5).

Antes de pasar al siguiente apartado, sobre la organización comarcal de Cataluña, sería preciso detenernos a observar la nueva configuración del mapa administrativo catalán.

En primer lugar parece existir una voluntad política firme de reestructurar el status quo existente en 1979. De hecho el Estatuto

(5) Las dos nuevas entidades metropolitanas eran: la Entidad Metropolitana del Transporte, formada por 18 municipios, orientada a prestar los servicios de transporte público de viajeros. Y la Entidad Metropolitana de Servicios Hidráulicos y de Tratamientos de Residuos, formada por 32 municipios, y diseñada para ofrecer los servicios de abastecimiento, tratamiento y evacuación de aguas, asi como el tratamiento y eliminación de residuos. 
de Autonomía, en su artículo 5, no hace referencia a la provincia como parte de la organización territorial de Cataluña. Se intenta vaciar de competencias a las Diputaciones Provinciales a la vez que institucionalizar la comarca como prestadores de servicios supramunicipales, teniendo funciones de «microdiputaciones». Se suprime la Corporación Metropolitana de Barcelona, sustituyéndola por dos entidades nuevas.

Por otro lado, desde el Gobierno Autónomo, se van creando diferentes Leyes y Reglamentos que introducen nuevos marcos de legislación del régimen local: Ley 23/1983, de 21 de noviembre, de Política Territorial, mediante la cual se establecen las directrices de organización territorial. La Ley 8/1987, de 15 de abril, Municipal y de Régimen Local de Cataluña, dictada en el marco de las bases estatales (6). Decreto 140/1988, de 24 de mayo, por el cual se aprueba el Reglamento de Demarcación Territorial y Población de los Entes Locales. Así como las anteriormente citadas Ley 5/1987, de Régimen Provisional de Competencias de las Diputaciones; Ley 6/1987, de Organización Comarcal, y la Ley 7/1987, sobre la conurbación de Barcelona.

En resumen, las diversas disposiciones legislativas se han dirigido, fundamentalmente, a:

1. ${ }^{\circ}$ Remodelar la administración local.

2. ${ }^{\circ}$ Asignar un nuevo marco territorial donde la Comarca se constituya en un ente supramunicipal.

3. ${ }^{\circ} \quad E$ intentar dotar bajo un nuevo marco legal y mediante nuevas leyes y reglamentos, la formalización jurídico-institucional del nuevo modelo de administración local.

\section{LA COMARCA}

La estructuración territorial en comarca ha estado en el punto de mira de numerosos políticos, geógrafos y pensadores en general, a lo largo de los últimos doscientos años. La herencia municipalista de la Revolución Francesa era cada vez más cuestionada a medida que el siglo XIX avanzaba en el tiempo (7).

(6) La Ley 7/1987, Reguladora de las Bases del Régimen Local, de 2 de abril, es la norma que recoge los aspectos básicos y comunes que rigen en todas las Administraciones Locales del Estado. En esta misma línea, el Real Decreto Legislativo 781/1986, de 18 de abril, refunde las disposiciones legales vigentes en materia de Régimen Local.

(7) Durante el siglo XIX el movimiento comarcalista catalán generó abundantes estudios sobre las demarcaciones territoriales de las comarcas. De entre estos estudios destacan los de CEBRIÁ I COSTA en 1864; AULĖSLIA I PIJOANI en 1887; FLOS I CALCAT en 1895, y ya en pleno siglo $X X$ el importante estudio de PAU VILA «EI problema comarcal de Catalunya». EI denominador común de todos estos estudios es la gran diversidad de sus resultados. Ninguno de ellos coincidía con los restantes en las demarcaciones comarcales. 
La clase política catalana del último tercio del siglo XIX comenzó, por aquel entonces, a articular propuestas políticas que hicieran resurgir la legitimidad de la antigua organización comarcal catalana como estructura territorial de organización política y administrativa. Las Bases de Manresa fue, podemos decir, la primera articulación programática que recoge la comarca como ente natural (8). En esta misma línea, los hombres de la "Lliga» formulaban la voluntad de revitalizar la organización comarcal (CAMBÓ, PRAT DE LA RIBA). También el catalanismo más radical, representado, entre otros, por FRANCESC MACIÀ manifestaba el rechazo a la administración provincial a favor de la organización comarcal (9).

Tras el advenimiento de la II República en 1931 y el reconocimiento de la Región Autónoma de Cataluña, se abre un nuevo capítulo. El Estatuto de Autonomía del 9 de septiembre de 1932, en su artículo 10, permitía (dentro de los confines legislativos básicos del Estado) al Gobierno de la Generalitat crear las demarcaciones territoriales que creyese conveniente. En virtud de lo cual se creó, como es conocido por todos, por el Decreto de 27 de agosto de 1936, una nueva división territorial organizada en comarcas y regiones. Organización que tuvo una vigencia efímera, debido a los acontecimientos políticos y bélicos de la guerra civil.

Con el final de la guerra civil se acabó también con la breve experiencia de la organización comarcal en Cataluña. Con la dictadura del General FrANCO se sucedió una auténtica contrarreforma: se suprimió toda la legislación republicana y se modeló un modelo de Estado con un fuerte centralismo administrativo y político.

Con la Constitución Española de 1978 se abre una nueva etapa constitucional. Se reconoce el acceso a la autonomía política y administrativa de los entes locales. En este sentido, y según los artículos 137, 140, 141 y sobre todo el 152, parece permitir la configuración de la comarca con ente local (10).

La Ley del Parlamento Catalán 6/1987, de 4 de abril, sobre la organización comarcal de Cataluña, es el primer reconocimiento

(8) En 1892 se aprueban las "Bases per a la Constitució Regional Catalana» (conocido comúnmente como "Las Bases de Manresa" por ser en esta ciudad donde se celebró su aprobación), la base quinta establecía la división territorial sobre la cual se habría de desarrollar la estructura jerárquica de los poderes "Gradació jeràrquica dels Poders governatius, administratius $\mathrm{i}$ judicials tindrà per fonament la comarca natural i el municipi».

(9) El proyecto de «constitució provisional de la República catalana» presentado por MACIẢ en La Habana en 1928 reconocía en su artículo séptimo que las divisiones provinciales quedarian abolidas dando paso a la organización por comarcas.

(10) El artículo 152 que hace referencia a los Organos de las Comunidades Autónomas, en su apartado 3, indica que «Mediante la agrupación de municipios limitrofes, los Estatutos lde Autonomía de las Comunidades Autónomas) podrán establecer circunscripciones territoriales propias que gozarán de plena personalidad jurídica». 
institucional -derivado del artículo 5 del Estatuto de Autonomíade antiguas formulaciones del catalanismo político, provenientes ya desde finales del XIX (11). Dicha Ley da vida jurídica a los entes comarcales y establece un nuevo modelo de organización territorial (12). Como veremos en el caso del Consell Comarcal del Baix Llobregat, la indefinición de este modelo hace que actualmente esté poco desarrollado y actúe a unos niveles muy básicos, casi simbólicos.

El modelo de administración supramunicipal ha tenido otros reflejos en diferentes países occidentales. La Comarca en Cataluña, los Condados ingleses o norteamericanos o el Kreis alemán, parecen ser el resultado tanto de organizaciones inicialmente informales, que pivotaban alrededor de un punto en común, en la mayoría de los casos mercados agrícolas o ganaderos, como de naturaleza meramente geográfica que agrupaba a diversos núcleos de población con un sentimiento de pertenencia.

En esta misma línea es preciso enfatizar que tanto la Ley Municipal y de Régimen Local como el Reglamento de Demarcación Territorial constatan que la Comarca es un ente de carácter local cuya base fundamental es el territorio (13).

(11) En la segunda república, como hemos indicado anteriormente, la Generalitat de Catalunya aprobó por Decreto en 1936 la promulgación, por primera vez, de la división comarcal de Catalunya en 38 comarcas. Esta nueva organización no fue todo lo eficiente de lo esperado, ya que la Generalitat de Catalunya inicialmente se organizó territorialmente en base provincial hasta el Decreto de 1936 y tras la supresión de éstas en Vegueries. Concretamente el Estatuto Catalán de 1932, en su artículo décimo, atribuía competencias exclusivas a la Generalitat de Catalunya sobre el régimen local y la división territorial, no reconociendo más ente local obligatorio que el municipio y señalaba que «... para el cumplimiento de sus fines la Generalitat podrá establecer las demarcaciones territoriales que estime más convenientes», derivándose de dicho precepto la creación y constitución de las comarcas, y desechando formalmente la idea de provincia.

Es preciso señalar que la eliminación del nivel provincial lo fue únicamente en su condición de ente local, se mantuvo, asimismo, para la prestación de servicios. La misma Generalitat utilizó la división territorial provincial para organizar sus servicios periféricos.

(12) Anteriormente a la Ley de Organización Comarcal de Catalunya se aprobaron dos Leyes sectoriales de incidencia territorial: La Ley 2/1983, de Alta Montaña, y la Ley 23/1983. de Política Territorial. Esta última sentaba las directrices de ordenación del territorio y de las acciones administrativas, donde corresponsabilizaba a los municipios de los objetivos establecidos en la misma. La Ley de Alta Montaña podemos catalogarla como el primer episodio para la implantación de un mapa comarcal en Catalunya. De hecho, dicha legislación creaba los Consells Comarcals de Montaña (extinguidos a partir de la LOCC), con el objetivo de desarrollar los respectivos planes comarcales de montaña. A pesar de que en dicha Ley no se cataloga la comarca de montaña como ente local, parece indudable que la Ley de Alta Montaña es el primer paso hacia la futura organización comarcal del territorio, aunque si bien, como manifiesta la Ley, en un ámbito reducido.

(13) El artículo 1 de la Ley 8/1987, de 15 de abril, sobre municipios y de régimen local de Catalunya, indica que "Los municipios y las comarcas son los entes locales en que se organiza territorialmente la Generalitat de Catalunya», aun asi también se reconoce en su artículo segundo que la provincia, las entidades municipales descentralizadas, las entidades metropolitanas y las mancomunidades de municipios, también tienen condición de entes locales de Catalunya. De igual forma el Decreto 140/1988, de 24 de mayo, por el cual se aprueba el Reglamento de 
El procedimiento para establecer la división comarcal de Cataluña queda regulado en el artículo 4 de la LOCC, en la que se incluye una consulta previa a los municipios implicados y la posterior aprobación mediante ley por la Generalitat de Cataluña. Asimismo, tanto una futura modificación de la demarcación comarcal como la creación de nuevas comarcas o el cambio de denominación y capitalidad, quedan regulados en los capítulos II, III y IV de la misma ley (14).

La articulación institucional de este ente Local se hace mediante el Consell Comarcal. Este es el máximo órgano de gobierno para los asuntos de carácter comarcal. La Ley de Ordenación Comarcal de Cataluña prevé, en este mismo sentido, que el Consell Comarcal se estructure en los siguientes órganos: Pleno, Presidente y Comisión Especial de Cuentas.

Resulta importante destacar la nueva figura del Gerente. Este cargo, de carácter profesional, tiene reconocidas sus funciones en el artículo 17 de la LOCC. Sin entrar en las valoraciones que, por ser una figura de reciente creación, el tiempo no nos permite, resulta importante destacar la voluntad del legislador por introducir una nueva figura, reconocida por ley, en la organización comarcal de Cataluña. Todavía es demasiado pronto para poder hacer una valoración en perspectiva de los problemas y aciertos de esta nueva figura. Desde nuestro punto de vista, creemos muy positivo dotar a esta figura, tal y como se ha hecho, de un margen de maniobra administrativa y de gestión (15).

El legislador, sensible a que algunos de los mayores problemas de la Administración Pública ha sido, y sigue siendo, la falta de elementos para una gestión innovadora y moderna, parece haber querido, mediante la creación de este cargo, apostar por un nuevo

Demarcación Territorial, en su artículo 1.1 indica que «El territorio es un elemento esencial del municipio y de la comarca» y en el artículo 1.2 «... el territorio de la comarca coincide con la demarcación comarcal, formada por el territorio de los municipios que agrupa».

(14) La Ley de Ordenación Comarcal preveía el establecimiento, como marco territorial, de la implantación de las 38 comarcas establecidas por la Generalitat Republicana en 1936. Estas 38 comarcas se ampliaron a 41 a través de los mecanismos de modificación de las demarcaciones comarcales previsto por la misma Ley. Tras la aprobación de esta Ley en abril de 1987, se pasó una consulta municipal a todos los municipios de Catalunya para que manifestaran su voluntad de aceptar o no la demarcación comarcal propuesta. De los 940 municipios consultados, 833 se manifestaron favorables a la integración en la comarca donde estaban insertos y 107 se manifestaron desfavorables. La Ley de 16 de diciembre de 1987 de División y Organización Comarcal de Catalunya aprobó la organización comarcal en 38 comarcas. Tres meses más tarde y mediante la Ley 5/1988, de 28 de marzo, se dio vía legal a tres nuevas comarcas: la del Alta Ribagorça, la del Pla de l'Estany y la del Pla d'Urgell, sumando así un total de 41 comarcas, número que se mantiene en estos momentos.

(15) Sometido como cualquier cargo público al imperio de la ley, a los reglamentos y leyes que correspondan, así como a las incompatibilidades establecidas por Ley. Sin olvidar que el Gerente es el brazo ejecutor y gestor de las directrices, orientaciones e instrucciones tanto del Consell Comarcal como de su Presidente, al cual se encuentra especialmente vinculado. 
modelo de administración. El acierto y oportunidad de dicha figura podrá ser evaluada justamente sólo cuando las comarcas estén dotadas de un margen de maniobra financiera y competencial de la cual actualmente carecen.

\subsection{Competencias y financiación comarcal}

Si importante es reconocer, vía legislación, la voluntad política en la creación de las comarcas, más importante es estudiar los niveles competenciales asignados, así como la autonomía financiera para poder llevarlas a cabo.

Parece obvio que para que las comarcas puedan ser consideradas auténticos entes administrativos, se les ha de dotar de autonomía en competencias y financiación. Ambos elementos, competencias y financiación, forman parte del mismo tándem. Estudiaremos a continuación ambos elementos.

\subsubsection{LAS COMPETENCIAS COMARCALES}

En cuanto a las competencias, se distinguen en:

\section{A) Competencias provenientes de la Generalitat}

En este sentido, el artículo 25.1 de la LOCC señala que las comarcas ejercerán las competencias atribuidas por las leyes del Parlamento de la Generalitat, las cuales comprenderán en todo caso las materias de: ordenación del territorio y urbanismo, sanidad, servicios sociales, cultura, deporte, enseñanza y salud pública y medio ambiente.

El escaso desarrollo legislativo de estas materias, a excepción de algunos decretos de agosto de 1989, que comentaremos más adelante, no permite dotar a las comarcas de una auténtica autonomía competencial. Las competencias reseñadas en el artículo 25.1 son competencias propias de la Generalitat que sectorialmente tenderá a descentralizar hacia las comarcas.

Otro bloque de competencias susceptibles de ser traspasadas a las comarcas son las que continúa ejerciendo la provincia. Competencias que, conforme con la legislación sectorial, deberán ser desarrolladas por la Generalitat.

También podrán las comarcas ejercer las competencias delegadas o asignadas por la Generalitat, de conformidad con la Ley 8/1987, Municipal y de Régimen Local de Cataluña, artículo 122 (16).

(16) Según el artículo 122.1 de dicha Ley, «La administración de la Generalitat puede delegar o asignar el ejercicio de competencias propias a los entes locales de Catalunyan. En el artículo 122.2 indica también, que "La delegación o la asignación es general. No obstante esto, 
Ahora bien, podemos señalar como competencias comarcales ya vigentes las derivadas del capítulo II de la Ley 23/1983, de Política Territorial, donde se reconoce a la comarca la iniciativa para la constitución de planes territoriales parciales (art. 12), la formación y gestión de los planes previstos para las comarcas de montaña por la Ley $21 / 1985$, de 27 de diciembre, o la intervención en la gestión de servicios sociales, de acuerdo con lo previsto en la Ley 26/1985, de 27 de diciembre.

\section{B) Competencias provenientes de los municipios}

Fundamentalmente son los servicios municipales propiamente mínimos. En la Ley Reguladora de la Bases del Régimen Local, y en su artículo 26.1, se recogen todos aquellos servicios que los municipios prestarán por sí mismos o asociados con otros municipios. En el artículo 26.2 de la misma Ley se prevé también que los municipios podrán solicitar, cuando el cumplimiento de esa obligación resulte imposible o de difícil cumplimiento, su dispensa a la respectiva Comunidad Autónoma.

La Ley Municipal de Régimen Local de Cataluña, en esta misma línea y en su artículo 66, faculta a la Comarca la posibilidad de asumir directamente la competencia para la prestación de servicios mínimos obligatorios, siempre previa autorización de la Generalitat y sin la oposición del municipio interesado. También se prevé la asunción directa para la comarca sin la necesidad de un expediente de dispensación, cuando concurran ciertos factores, como insuficiencia financiera del municipio, una población diseminada en varios núcleos de población sin que ninguno supere más de $\mathbf{5 0}$ habitantes o cuando las partidas presupuestarias para retribuir las funciones públicas necesarias superen el 50 por 100 de su capacidad financiera.

En resumen, para que se pueda dar una cierta comarcalización de las competencias municipales es preciso que se den unos requisitos muy cualificados, previstos en los artículos 30 y 32 de la Ley de Ordenación Comarcal de Cataluña. Los requisitos para la conversión de las competencias municipales en comarcales, son los siguientes: que la Ley lo establezca expresamente o atribuya la competencia alternativa al municipio o a la comarca, que exista una mayoría absoluta en el pleno del Consell Comarcal, que no exista oposición por la mayoría de los municipios afectados o por municipios que sumen más de la mitad de la población de la

puede ser específica para uno o diversos entes por motivos de capacidad económica y de gestión, por el número de habitantes, por la naturaleza o las características del servicio, o si concurren otras circunstancias objetivas que lo justifiquen»). 
comarca, y por último, que se trate de competencias no cualificadas de mínimas de acuerdo con el artículo 26 de la LRBRL.

Las comarcas también tendrán la facultad de ejercer medidas de coordinación para la prestación de servicios de interés comarcal. Asimismo también en cada comarca podrá haber un servicio de cooperación y asistencia municipal encargado del asesoramiento de los municipios que lo soliciten en materia jurídico-administrativa, económica y financiera y de obras y servicios (art. 33 de la LOCC). Medidas de coordinación y cooperación y asistencia que coinciden, casi absolutamente, con las que tienen las Diputaciones Provinciales. Siendo esto otra dificultad a agregar al ya poco definido marco competencial de las comarcas.

Esta división utilizada, entre competencias provenientes de la Generalitat y las provenientes de los municipios, está basada, como se observa, en función de la procedencia, es decir de donde provienen o pueden provenir las competencias. Ni que decir tiene que el tema de las competencias puede ser estudiado desde diversos puntos de vista, por ejemplo desde su ámbito material -donde la concurrencia o compartición será inevitable- o por su naturaleza jurídica -competencias exclusivas, compartidas o concurrentes.

En resumen, hemos visto que las competencias de la Generalitat o de las Diputaciones Provinciales - una vez solventado el contencioso al respecto- se harán mediante Leyes sectoriales o por vía de convenios. En cambio, en el caso de las competencias municipales la concesión o delegación puede provenir de varias vías, ya referidas anteriormente.

\subsubsection{LA FINANCIACIÓN COMARCAL}

La Hacienda Comarcal. Para finalizar este apartado introductorio sobre las comarcas, será preciso concluir con uno de los temas más espinosos de cualquier administración pública: su financiación.

La LOCC, en su artículo 43, determina cuáles serán las fuentes de financiación y recursos para las Haciendas Comarcales.

Siguiendo la división simplificada que hemos utilizado anteriormente cuando hablábamos de las competencias, utilizaremos, asimismo, la misma división, entre recursos provenientes de la Generalitat o del Estado y los que provienen de los municipios y de las Diputaciones, más los generados por la comarca.

\section{A) Recursos derivados del Estado o de la Generalitat}

El artículo 43.1, d), de la LOCC hacía referencia expresa a este tema. Así se indicaba que la comarca podría beneficiarse de los 
ingresos del Estado y de la Generalitat, siempre que estos órganos superiores así lo determinen.

Ya desde los inicios, este punto parecía de difícil realización. Por lo menos a corto plazo no parecía muy probable que el Estado estableciera una participación en sus impuestos a favor de las comarcas. Esta negativa a la cooperación del Estado en la financiación de las comarcas se concreta en la afirmación del artículo 136 de la Ley 39/1988, de 28 de diciembre, Reguladora de las Haciendas Locales. Este artículo establece que las comarcas no podrán exigir impuestos o recargos, ni participación en los tributos que recaude el Estado y que refiere dicha Ley. $Y$ concluye, en su punto segundo, que las Comunidades Autónomas son las responsables de determinar los recursos económicos que se les asignen.

Quedaba así claro, por tanto, que el desarrollo del modelo comarcal en su vertiente financiera era responsabilidad única y exclusiva del gobierno de la Comunidad Autónoma en cuestión.

En el caso que nos ocupa, una de las pocas posibilidades factibles, si se quiere desarrollar el modelo comarcal, es que la Generalitat permita una participación de las comarcas en los escasos impuestos que recauda unilateralmente (apuestas y juegos fundamentalmente). Por otro lado, la Ley de Organización Comarcal de Cataluña, prevé en el artículo 44 que la Ley de Presupuestos de la Generalitat establecerá un porcentaje de participación a favor de las comarcas en el Fondo de Cooperación Local de Cataluña. Vía ésta que ha comenzado a utilizarse como forma de garantizar unos servicios mínimos en la actual fase embrionaria de la comarca.

\section{B) Recursos derivados de las Diputaciones o de los municipios}

La posibilidad de obtener participaciones de los ingresos provinciales, viene recogida en el artículo 43.2 de la LOCC. En este sentido la Ley indica que las comarcas podrán obtener participaciones provinciales, en el momento que se asuman las competencias de éstas y tal y como quede dispuesto por la Generalitat. Parece obvio que esta posible fuente de financiación parece actualmente de difícil ejecución. Hasta que no se solucione el tema de la existencia o no de las Diputaciones Provinciales, así como quién asumiría inicialmente los recursos provinciales si la Generalitat directamente o las comarcas, o cómo se distribuirían los ingresos, parece que a medio plazo esta fuente de financiación parece, más bien, de difícil acceso.

Los posibles ingresos derivados de los municipios quedan recogidos en el artículo 45 de la Ley de Ordenación Comarcal de Cataluña. En dicho artículo se indica que las finanzas comarcales se nutrirán también de las aportaciones de los municipios. Aportacio- 
nes que estarán en función de parámetros de proporcionalidad como del número de habitantes o del aprovechamiento efectivo del servicio comarcal por parte de municipio. Hoy por hoy, esta vía no está suficientemente desarrollada. No todos los municipios participan en estos ingresos y los que lo hacen, lo hacen por criterios más simbólicos que de eficacia financiera.

Las comarcas también recabarán de sus municipios tasas por la prestación de servicios o por la realiżación de obras. En cualquiera de los casos, estas contribuciones del municipio o municipios beneficiados hacia el Consell Comarcal, serán siempre condicionadas para la operación efectuada, es decir, para la financiación de la obra o servicio prestado.

\section{C) Recursos propios}

Estos serían tanto los derivados del derecho privado, es decir, aquellos que provengan de los propios patrimonios, como del derecho público, como multas, etc.

Desde la óptica de la distribución competencial, el marco de financiación comarcal se concretaría, de manera sucinta, en los siguientes modos: para las competencias llamadas propias, que serían las derivadas de Leyes de carácter sectorial provenientes de la Generalitat, su financiación se haría mediante el Fondo de Cooperación Local de Cataluña. Para aquellas competencias delegadas por la Generalitat, se deberá acompañar en el mismo paquete sus formas de financiación. De las competencias asumidas del municipio o de la provincia su financiación quedará condicionada a la forma como se asuma.

Para concluir sería preciso indicar, remitiéndonos al cuadro anteriormente expuesto, que si el modelo comarcal es difícilmente definible desde el punto de vista competencial, más dificultades presenta, aún, desde su aspecto financiero. En último extremo la financiación comarcal dependerá, por lo menos en sus momentos embrionarios, de los recursos que insufle la Generalitat.

\section{EL CONSELL COMARCAL DEL BAIX LLOBREGAT (17)}

En 1987 la Generalitat, mediante el Departamento de Gobernación, realizó una encuesta en todos los municipios de Cataluña.

(17) El Baix Llobregat es la segunda comarca, de las 41 existentes, y tras el Barcelonès, con mayor densidad de población. En 1986 se encontraban censados en esta comarca alrededor de 520.000 habitantes, con una densidad de 1.095 habitantes/kilómetro cuadrado. Desde el punto de vista geográfico el Baix Llobregat se extiende desde Montserrat hasta el Mediterráneo. Históricamente su denominador común fue el cauce del río Llobregat, del cual extrae su nombre. 
Dicha encuesta se dirigía a intentar conocer la adscripción o no a la comarca en la que estaban insertos. Las clásicas tensiones del mapa local catalán se manifestaron en las respuestas al cuestionario.

Por lo que respecta al Baix Llobregat, se destacaba que: Esplugues de Llobregat y Sant Just Desvern, pertenecientes al Barcelonés, querían pasar a formar parte del Baix Llobregat. En este sentido los municipios de Cornellá de Llobregat, Sant Andreu de la Barca, Sant Joan Despí, Gavà y San Vicenç dels Horts, condicionaron su pertenencia al Baix Llobregat a la admisión en esta comarca de Esplugues y Sant Just. Por otro, la de Begues aceptó su adscripción al Baix Llobregat, pero declarando su voluntad futura de adherirse al Alt Penedès; parece ser que la idiosincrasia de Begues, más cercana al Alt Penedès erı temas vitivinícolas y de denominación de origen de sus caldos, dejó abierta una posible adhesión futura al Alt Penedès. Abrera, Esparreguera, Olesa de Montserrat y Sant Esteve Sesrovires, junto con Masquefa (que pertenece a la comarca del Anoia), manifestaron voluntad de crear una nueva comarca denominada Baix Llobregat Nord o Montserrat, con centro en Martorell. Martoreill no se manifestó al respecto (18).

En cualquiera de los casos, al día 31 de enero de 1990, los municipios que pertenecían a la Comarca del Baix Llobregat eran los siguientes:

Abrera, Begues, Castelldefels, Castellví de Rosanes, Cervelló, Collbató, Corbera de Llobregat, Cornellà de Llobregat, Esparreguera, Esplugues de Llobregat, Gavà, Martorell, Molins de Rei, Olesa de Montserrat, Pallejà, El Papiol, El Prat de Llobregat, Sant Andreu de la Barca, Sant Boi de Llobregat, Sant Climent de Llobregat, Sant Esteve Sesrovires, Sant Feliu de Llobregat, Sant Joan Despi, Sant Just Desvern, Sant Vicenç dels Horts, Santa Coloma de Cervellá, Torrelles de Llobregat, Vallirana y Viladecans.

\footnotetext{
Algunos de sus municipios más importantes están englobados dentro del área metropolitana de Barcelona. Es una comarca fuertemente marcada por la proximidad de Barcelona. Desde el punto de vista económico, es un área con un extenso suelo industrial.

(18) Al comparar esta información con la que facilitó la División Territorial de la Generalitat Republicana, y según los autores del libro "L'Economia del Baix Llobregat», se observa que «... la encuesta de la Ponencia de la División Territorial de la Generalitat Republicana, a la pregunta de "¿a qué comarca pertenece?". coincide bastante con las respuestas de los Ayuntamientos actuales, ya que Gelida, Esplugues de Llobregat, I'Hospitalet de Llobregat y Sant Just Desvern querían integrarse al Baix Llobregat. En cuanto a la pregunta " ¿a qué mercado van?", las respuestas mostraban dos puntos de atracción principales: Martorell, para un buen número de municipios de la mitad norte de la comarca y Barcelona para los de la mitad sur. Todo esto hace que la referencia a los años treinta todavia sea vigente: la diferencia entre la mitad norte y la mitad sur y la demanda de adscripción al Baix Llobregat de ciertos municipios del Barcelonès». Véase L'Economia del Baix Llobregat. Creixement i Desequilibris, VV.AA. Caixa d'Estalvis de Catalunya. Colecció Catalunya Comarcal, 1989. pp. 12 y ss.
} 
En total, 29 municipios, tras la adhesión de Sant Just Desvern y Esplugues (19).

\subsection{El Reglamento Orgánico del Consell Comarcal del Baix Llobregat}

Los Consells Comarcals, como entidades locales de naturaleza territorial, tienen reconocidos la potestad autoorganizativa, consecuencia lógica de su autonomía administrativa. Tanto la Ley Reguladora de las Bases del Régimen Local, de normativa básica para todo el Estado, como la Ley Municipal y de Régimen Local de Cataluña reconocen la autonomía administrativa y reglamentaria de las Administraciones Locales (20).

El Reglamento Orgánico del Consell Comarcal del Baix Llobregat (ROCCBLL), fruto de esta autonomía organizativa, reconocida por ley, fue aprobado por unanimidad y en sesión plenaria el día 14 de junio de 1988.

El ROCCBLL, tal y como indica en su preámbulo, es la norma suprema a nivel organizativo por la que se rige la entidad comarcal y ues fonamenta bàsicament amb el respecte als Principis Constitucionals de Autonomia Local, submissió al Principi de legalitat i respecte dels drets reconeguts en la nostra constitució a tots els ciutadans».

EI Reglamento mediante el cual se organiza el Consell Comarcal del Baix Llobregat tiene por objeto la regulación del régimen organizativo y de funcionamiento de los servicios comarcales, regulando tanto sus órganos de gobierno como el régimen jurídico de su funcionamiento. Como indica el artículo $2 .^{\circ}$ del ROCCBLL, éste es «la font normativa bàsica a nivell organitzatiu d'aquest Consell Comarcalı.

El espíritu del reglamento, y de acuerdo con el artículo 103 de la Constitución, se inspira en criterios de eficacia, rapidez $y$

(19) La Ley 3/1990, de 8 de enero, de Modificación de la División Comarcal de Catalunya, dio el camino jurídico a la plena incorporación de los municipios de Esplugues y Sant Just Desvern a la comarca del Baix Llobregat. Con esta aprobación se da respuesta a la voluntad expresada con anterioridad de los municipios citados de pertenecer al Baix Llobregat. No obstante y según lo establecido por ley la composición del Consell Comarcal no se modificará hasta las próximas elecciones municipales.

(20) El artículo 8.1 de la Ley $8 / 1987$, de 15 de abril, Municipal y de Régimen Local de Catalunya, lista las competencias en materia de potestad legislativa de los entes locales: "Com a administracions públiques corresponden als ens locals territorials de Catalunya, en l'ambit de llurs competències $i$ en els termes establerts per la legislació de règim local, les potestats següents: a) Reglamentària i la d'autoorganització. b) La tributària i la financera, c) La de programació o de planificació. d) L'expropiatòria. e) La d'investigació, d'atermenaments i de recuperació d'ofici de llurs béns. f) La d'execució forçosa i la sancionadora. g) La de revisió d'ofici de llurs actes i acords». 
transparencia en la actuación comarcal, por tal de que tanto municipios como ciudadanos se sientan integrados en la comarca, «... (i) que els baixllobregatins arribin a sentirse protagonistes dels assumptes públics de la seva Comarca i no merament administrats».

\subsection{Los órganos de gobierno del Consell Comarcal del Baix Llobregat}

El artículo 4 del ROCCBLL reconoce explícitamente que la administración comarcal está integrada por el Presidente y los Consejeros, y su ejercicio se hará mediante el Pleno, la Comisión de Gobierno y el Presidente, «... sense perjudici de les delegacions que es preveu... i de les funcions executives del Gerent, determinades per la Llei»).

El Presidente del Consell Comarcal:

La figura de Presidente del Consell Comarcal queda reconocida en el artículo 5 del Reglamento Orgánico. Sus atribuciones son las siguientes: representar al Consell Comarcal, convocar y presidir las sesiones del Pleno y la de otros órganos colegiados, supervisar las obras comarcales y los servicios de la administración de la comarca, ejercer la dirección superior del personal, las acciones judiciales y administrativas en caso de urgencia, ordenar la publicación de los acuerdos y las atribuidas por las leyes que expresamente otorgue el Pleno (21).

El Pleno:

El artículo 9 del ROCCBLL reconoce como Organo de Gobierno Comarcal al Pleno, integrado por todos los Consejeros y por el Presidente a su cabeza. El artículo 10 ofrece una extensa lista de las atribuciones que corresponden al Pleno, entre ellas destaca que es el Pleno quien elige al Presidente, el que aprueba los Reglamentos Orgánicos y las Ordenanzas, el que aprueba y modifica los presupuestos, aprueba los Planes Comarcales, delega competencias en los municipios, elige y separa al Gerente y controla y fiscaliza la gestión de los Organos de Gobierno. En suma, todas aquellas funciones necesarias para la administración comarcal.

Es de destacar, también, que el artículo 10.2 permite al Pleno del Consell Comarcal delegar competencias a favor del Presidente

(21) Desde el punto de vista comparativo, el artículo 5 y ss. del Reglamento Orgánico del Consell Comarcal del Baix Llobregat, es una reproducción calcada de las competencias que el artículo 14 de la Ley $6 / 1987$, de 4 de abril, sobre la Organización Comarcal de Catalunya, atribuye a la figura de los Presidentes de los Consells Comarcals. 
o de la Comisión de Gobierno. Así como delegar competencias a favor del Gerente en temas de autorización y disposición de gastos (22).

\section{La Comisión de Gobierno:}

Es el órgano colegiado que bajo la presidencia del Presidente está integrado por un número de Consejeros que no puede superar un tercio de los miembros que componen el Consell Comarcal (artículo 11). El Presidente tiene la facultad de designar y separar libremente a los miembros de la Comisión de Gobierno, con la única premisa de informar al Pleno.

Como órgano colegiado que es, la Comisión de Gobierno tiene la competencia básica de la prestación de asistencia al Presidente en el ejercicio de sus atribuciones. El artículo 12 lista las competencias delegadas o susceptibles de delegación, a la Comisión de Gobierno (23).

\section{Los Vicepresidentes:}

El ROCCBLL, en su artículo 13, reconoce la figura del Vicepresidente. Según el Reglamento pueden haber uno o varios Vicepresidentes. Pero siempre serán designados, mediante Decreto, por el Presidente del Consell Comarcal, el cual dará cuenta al Pleno en la primera sesión que se celebre tras la designación.

El Vicepresidente tiene la facultad de sustituir al Presidente en casos de ausencia, vacante o impedimento. También puede obtener delegaciones de carácter general del Presidente.

\section{La figura del Gerente:}

Tal y como recoge el artículo 17 de la Ley 6/1987 sobre la organización comarcal de Cataluña, introducir el cargo de Gerente manifiesta la voluntad del legislador de dotar al Consell Comarcal una figura con carácter gerencial-profesional.

En esta misma línea, el Reglamento Orgánico del Consell Comarcal del Baix Llobregat reconoce, en su artículo 18, las

(22) Al igual que en el caso de las competencias atribuidas al Presidente, las del Pleno reproducen casi literalmente las asignadas por la Ley $6 / 1987$, artículo 15 , sobre las atribuciones competenciales del Pleno.

(23) La Comisión de Gobierno no prevista en el capitulo I del título III de la Ley 6/1987 de la organización comarcal, supone, en lo que respecta a la organización administrativa del Consell Comarcal del Baix Llobregat, una nueva figura de carácter colegiado. Figura que tiene su reflejo en el Consejo de Ministros del gobierno central o en el Consell Executiu del gobierno autónomo. 
atribuciones que de acuerdo con las directrices del Pleno y de las instrucciones del Presidente se les atribuye al cargo (24).

Tal y como observamos, la figura del Presidente del Consell Comarcal tiene una relativa prevalencia sobre el resto de órganos de gobierno. Sus facultades, tanto las designadas por Ley como las derivadas de la designación de los componentes de la Comisión de Gobierno o de los Vicepresidentes, así como de las delegaciones especiales que haga el Presidente hacia otros Consejeros (art. 16), le dan un carácter, a primera vista, de especial prevalencia. Prevalencia que queda reducida a un presidencialismo débil por ser mero Presidente de un órgano colegiado. En cambio, la figura del Gerente, brazo director y ejecutor de los acuerdos del Pleno, así como de las instrucciones del Presidente, parece estar dotada de una mayor fortaleza administrativa y gerencial.

Podríamos afirmar que la estructura orgánica de comarcal está inspirada en un modelo de "presidencialismo débil» con una figura gerencial de relativa importancia.

\section{EL CONSELL COMARCAL DEL BAIX LLOBREGAT: UNA NUEVA ADMINISTRACION LOCAL}

El 9 de marzo de 1988 se constituyó en reunión solemne el primer Consell Comarcal del Baix Llobregat. Dieciséis meses más tarde se inaugura su sede. El 14 de julio de 1989 se estrenan las dependencias habilitadas para ello (25). Las dependencias se hallan en el Parc de Torreblanca que a su vez se encuentra dentro de la demarcación territorial de tres municipios: Sant Just Desvern, Esplugues y Sant Feliu de Llobregat.

Una de las primeras características del Consell Comarcal del Baix Llobregat proviene desde sus inicios. A diferencia de otras comarcas, la comarca del Baix Llobregat nace con competencias. Dichas competencias provienen de la extinta Corporación Metropolitana de Barcelona. Cuando en 1987 desaparece dicha Corporación, el Consell Comarcal del Baix Llobregat hereda cinco de las competencias que hasta entonces venía desarrollando la Corporación Metropolitana: parques metropolitanos, obras de ejecución urbanísticas que se refieran al Pla General d'Ordenació Urbana, el Eix de

(24) Al igual que en los anteriores órganos de gobierno, las funciones atribuidas al Gerente, son un calco exacto de las que la Ley 6/1987 atribuye a dicha figura.

(25) Hasta el asentamiento definitivo en el Parc de Torreblanca en el mes de julio, el personal administrativo del Consell Comarcal estaba compuesto por dos administrativas, una cedida por el Ajuntament de Cornellá y otra por el de Sant Feliu; ambas trabajaban en sus respectivos consistorios a las órdenes de la Gerente que operaba desde el área metropolitana. 
Promoció Agricola, el Servi de Desinsectació de Mosquits y el Cementiri Metropolità de Roques Blanques (El Papiol) (26).

El problema prioritario es, desde sus inicios, la financiación. Ya que a pesar de que se dispone de las competencias, se carece de recursos. La escasa correspondencia entre competencias asumidas y recursos y la imposibilidad de recaudar impuestos, hace que la autonomía financiera dependa, en última instancia, de los ingresos de la Generalitat. Estos ingresos provienen básicamente del Fondo de Cooperación Local de Cataluña. La magnitud y distribución del cual no parece permitir para esta comarca una gran autonomía financiera (27).

El Consell Comarcal elige sus miembros en función - de lo indicado en el artículo 20 de la LOCC. El total del Consellers del Baix Llobregat está formado por 38 miembros elegidos en segundo grado. Con la siguiente distribución por partidos políticos: 18 (47,37 por 100) del Partit Socialista de Catalunya, 11 (28,95 por 100) de la Coalición CIU, 7 (18,42 por 100) de Iniciativa per Catalunya, 1 (2,63 por 100) del Partit dels Comunistes de Catalunya y 1 (2,63 por 100) del Centro Democrático y Social.

El Presidente del Consell Comarcal es José Montilla, Alcalde a la vez del Ayuntamiento de Cornellá. Existe una Junta de Gobierno, de número más reducido, formada por representantes de cada partido.

\subsection{Los primeros traspasos competenciales}

Durante el mes de agosto de 1989 se publicaron desde la Presidencia de la Generalitat diversos decretos que delegaban, por primera vez (después de veinte meses de la constitución legal de los Consells Comarcals), el primer bloque de competencias delega-

(26) Los traspasos se realizan según el acuerdo suscrito con fecha 14 de diciembre de 1987 en el seno de la Comisión Mixta prevista en el apartado segundo de la disposición adicional segunda de la Ley $7 / 1987$, de 4 de abril.

A pesar de que en dicha Comisión Mixta no se llegaron a acuerdos de conjunto, la transferencia de servicios de la extinta Corporación Metropolitana de Barcelona, en lo que se refiere a la comarca del Baix Llobregat, quedó, como hemos referido más arriba, en cinco servicios transferidos: Parques Metropolitanos, Ejecución de Urbanismo, Cementerio de Roques Blanques, Eix de Promoció Agrícola y Desensectació.

La Generalitat dirigió a la comarca del Baix Llobregat, para la financiación de dichos servicios, un total de 221.100 .000 pesetas, que quedaron repartidos en las siguientes partidas: para personal, 14.800 .000 pesetas; para compras, 71.400.000; en transferencias, 36.000 .000 ; para deudas 12.900.000, y para inversiones previstas en 1988, 86.000.000 de pesetas.

(27) El Consell Comarcal del Baix Llobregat, a través de sus servicios jurídicos, interpuso en el mes de abril de 1989 un recurso contencioso-administrativo contra el Decreto 18/1989 de la Generalitat, mediante el cual se establecían los criterios de distribución del Fondo de Cooperación Local de Catalunya. El motivo aducido para interponer dicho recurso venía motivado por considerar que dicho Decreto atenta a los principios de autonomia y de suficiencia financiera. 
das. Las competencias delegadas de la Generalitat de Cataluña a las comarcas lo eran en materia de enseñanza, de sanidad, de bienestar social y de cultura.

Los decretos que regulaban estas transferencias eran de carácter general, es decir, para todas y cada una de las 41 comarcas de Cataluña.

El Consell Comarcal del Baix Llobregat, en sesión plenaria del día 10 de octubre de 1989, aprobó por unanimidad la asunción de las competencias recogidas en los diversos decretos de Presidencia. Se creó a la vez una Comisión para suscribir los diferentes convenios reguladores con la Generalitat, con el objetivo de poder hacer efectivos los diferentes traspasos competenciales, así como para determinar los elementos económicos, personales e infraestructurales que puedan permitir la prestación de dichos servicios.

Competencias delegadas a los Consells Comarcals:

Enseñanza (Decreto 219/1989):

Transporte escolar, gestión del transporte colectivo y de ayudas individuales de desplazamiento. Escoles-llar, establecimiento y gestión. Becas y ayudas para comedores escolares y cantinas. Programación y gestión de colonias y convivencias escolares, así como becas y ayudas.

Sanidad. ICASS (Orden de 17 de mayo de 1989):

Gestión y prestación de los servicios de atención primaria básica de los municipios con población inferior a 20.000 habitantes.

Bienestai social (Decreto 220/1989):

Establecimientos de acogida residencial para personas con disminuciones. Programas de fomento a la iniciativa privada para la prestación de servicios sociales residenciales para disminuidos. Promoción para su integración social. Supresión de las barreras arquitectónicas, coordinación y programación de servicios de transporte para personas con disminuciones. Promoción para su integración laboral.

Cultura (Decreto 208/1989):

Gestión de archivos históricos comarcales y de los archivos históricos de alcance inferior a la comarca. Gestión de los centros de normalización lingüística de alcance comarcal, participación en el procedimiento de concesión de las subvenciones a los Ayuntamientos en infraestructuras culturales. 


\section{BALANCE: DOS AÑOS DE ACTUACION DEL CONSELL COMARCAL DEL BAIX LLOBREGAT}

A partir de la constitución formal del Consell Comarcal en el mes de marzo de 1988, se han ido sucediendo actuaciones de diversa índole. Como veremos después, el fomento del «espíritu» comarcal ha sido uno de los objetivos más directos de esas acciones. La fórmula empleada se ha dirigido fundamentalmente a desarrollar acciones de carácter supramunicipal, aunque también es cierto que ha actuado, en algunos casos, como subsidiario de municipios concretos ante problemas puntuales (por ejemplo en las inundaciones de noviembre de 1988). A lo largo de estos escasos dos años el Consell Comarcal del Baix Llobregat ha ido aumentando su radio de influencia (directa o indirectamente) sobre los 29 municipios que componen la comarca.

A continuación resumiremos algunas de las acciones de mayor relevancia, emprendidas desde el Consell Comarcal del Baix Llobregat:

- La sesión plenaria del Consell Comarcal aprobó el día 14 de junio de 1988 el convenio de colaboración con el Centre d'Informació i Desenvolupament Empresarials (CIDEM) para la promoción de la comarca del Baix Llobregat. El convenio de colaboración declaraba en su primer capítulo el interés de coadyuvar a la promoción de la comarca en sus aspectos económicos, industriales, sociales y laborales, con el objetivo de promover condiciones más favorables para el progreso socio-económico de la comarca. Dicho convenio instaba, también, al Consell Comarcal al compromiso de constituir éste un organismo autónomo local dependiente del mismo. El mismo día 14 de junio, el Consell Comarcal aprobó la constitución del «Patronat Comarcal per a la Promoció del Baix Llobregat», entidad que actúa con personalidad jurídica propia e independencia económica y fundacional.

- La Comisión de Gobierno, en sesión celebrada el día 5 de julio de 1988, aprobó la moción de la Presidencia de fecha 21 de marzo para la adhesión de la comarca del Baix Llobregat al Pacte per a la Promoció del Baix Llobregat (28). Dicha adhesión preveía la Constitución de la Mesa Comarcal d'Ocupació con representación del Consell Comarcal.

(28) El pacte per a la Promoció del Baix Llobregat fue un acuerdo suscrito en el mes de diciembre de 1987 para la potenciación económico-social, la promoción del empleo y el desarrollo de las relaciones laborales, con una vigencia hasta el 31 de diciembre de 1988. Las Partes firmantes fueron las organizaciones y entidades representativas de CC.OO., UGT, SEFES, FESALC, FCTAC y los Ayuntamientos de Cornellà, Esplugues, Martorell y Sant Feliu. 
- Moción presentada por la Presidencia del Consell Comarcal, según el acuerdo en Pleno del día 20 de septiembre de 1988, para que el Programa Nacional d'Interés Comunitari (PNIC), considerase a todos los municipios de la comarca, y no sólo a algunos tal y como preveía, como zona industrializada en declive. Dicha moción se dirigió al Ministerio de Economía y Hacienda y al Conseller d'Economia i Finances de la Generalitat de Cataluña.

- Colaboración desde la Gerència de Promoció Agrícola con las cooperativas que comercializan las Cireres del Baix Llobregat. Elaborando un convenio de colaboración para la denominación de calidad.

El Patronato de Promoción Agrícola realizó obras de emergencia tras las inundaciones de finales de 1988. Se pavimentaron caminos agrícolas así como algunos drenajes en el delta occidental.

- Diversas actuaciones de tipo urbanístico en los municipios más afectados tras las inundaciones de noviembre de .1988. Las actuaciones fueron desde la reconstrucción parcial de algunas rieras hasta la reposición de puentes o muros de contención y acondicionar caminos afectados, así como diversas gestiones para conseguir financiación institucional. Los municipios que recibieron algún tipo de ayuda fueron: Sant Vicenç dels Horts, Sant Climent de Llobregat, Viladecans, El Prat de Llobregat, Castellví de Rosanes, Sant Boi de Llobregat, Torrelles del Llobregat, Santa Coloma de Cervelló, Olesa de Montserrat, Begues y El Papiol.

- Convenio para la creación de un centro para la rehabilitación y tratamiento de toxicómanos en el municipio de Sant Feliu de Llobregat, firmado por el Consell Comarcal y la Generalitat de Cataluña el 2 de marzo de 1989.

- Con fecha 14 de marzo de 1989 se aprobó por el Pleno del Consell Comarcal la constitución del Patronat Comarcal per la Promoció Agrícola del Baix Llobregat (29). Esta potestad organizativa mediante gestión directa se desarrolló conforme a lo previsto en el artículo 85.3, b), de la Ley Reguladora de las Bases del Régimen Local y en concordancia con los artículos 233 y 237 de la Ley Municipal y de Régimen Local de Cataluña.

El objetivo de la creación del Patronat era asegurar una prestación directa de sus servicios a través del organismo autónomo local creado. Las finalidades del Patronat se dirigen, tal y como señalan sus estatutos, a promover, conservar y procurar la adecuada utilización del suelo rústico de carácter agrícola en el ámbito

(29) Como consecuencia del Decreto $5 / 1988$, de 13 de enero, de transferencias de servicios de la Entitat Municipal Metropolitana de Barcelona, se transfirió al Consell Comarcal del Baix Llobregat el servicio de promoción agrícola, llamado "Eix de Promoció Agrícola».

REVISTA DE ESTUDIOS. -10 
comarcal, así como desarrollar, promover y participar en actuaciones de carácter intermunicipal a partir de las competencias municipales en materia de actividades agrícolas.

También se aprobaron en el mismo día los estatutos reguladores del Patronat Comarcal, estatutos que en su artículo 8 regulan la composición de la Junta de Gobierno y que quedará compuesta por siete Consejeros comarcales, un representante de la Unió de Pagesos y un representante de la Càmbra Agrícola Provincial.

- Con fecha 14 de abril de 1989 se firmó también un convenio de colaboración suscrito entre los Ayuntamientos afectados por la plaga de mosquitos del delta del río Llobregat y el aeropuerto internacional del Prat de Llobregat.

- El Pleno del Consell Comarcal aprobó con fecha 12 de mayo de 1989 la convocatoria para la concesión de subvenciones a los municipios de la comarca para la adquisición de telefax así como las bases que la rigen (30).

Las subvenciones para la adquisición de los telefax ascendían, para cada municipio solicitante y que cumpliera las condiciones de las bases reguladoras de la convocatoria, a 133.627 pesetas.

Tras diferentes plazos abiertos para la presentación de solicitudes, a mediados del mes de febrero de 1990 y de los 29 municipios que forman la comarca, 20 municipios habian solicitado subvención para la adquisición del telefax (31).

- Convenio de colaboración firmado el 30 de junio de 1989 entre el Consell Comarcal del Baix Llobregat y el Centre d'Estudis Comarcals del Baix Llobregat, para la elaboración de un atlas y mapa comarcal.

- Diversas actividades a lo largo del segundo semestre de 1989 (manifestaciones institucionales, fiestas, declaraciones, etc.) destinadas a promover que el asentamiento de la Cuarta Universidad tenga su sede en la comarca.

- El día 31 de octubre de 1989 se aprobó, mediante Comisión de Gobierno, la adjudicación al Grup d'Estudis Tecnics Territorials de la primera fase del Programa d'Actuació Comarcal por un total de 4.368.000 pesetas. La adjudicación se realizó en los términos previstos en el pliego de condiciones tipo aprobado por sesión plenaria de 15 de noviembre de 1988 y por el pliego de condicio-

(30) Las bases reguladoras de la convocatoria para la concesión de subvenciones a los municipios comarcales, destinadas a la adquisición de equipos de telefax, apareció publicado en el Butlleti Oficial de la provincia, con fecha 6 de junio de 1989

(31) Estos municipios eran: Abrera, Begues, Castelldefels, Castellvi de Rosanes, Corbera de Llobregat, El Papiol, El Prat de Llobregat, Esparreguera, Olesa de Montserrat, Pallejà, Sant Andreu de la Barca, Sant Climent de Llobregat, Sant Esteve de Sesrovires, Sant Feliu de Llobregat, Sant Just Desvern, Sant Vicenç dels Horts, Santa Coloma de Cervelló, Torelles de Llobregat, Vallirana y Viladecans. 
nes particulares aprobado por la Comisión de Gobierno el 11 de julio de 1989.

El Programa d'Actuació Comarcal, previsto por el artículo 27 de la Ley 6/1987 (32), tiene como objetivo tanto el cubrir con las previsiones legales como el conocer en profundidad los déficit comarcales por tal de establecer un plan de prioridades relacionadas con los diferentes sectores de actuación de la comarca. Tal y como se indican en el acuerdo aprobado el 11 de julio de 1989 , el Programa d'Actuació Comarcal consta de dos fases (con un total presupuesto de 7.840 .000 pesetas), la primera fase de recogida de datos y diagnosis de la situación y la segunda fase de terminación de objetivos y redacción del Programa d'Actuació Comarcal, parte que incluirá una memoria descriptiva y justificativa, un estudio económico-financiero, un plan de etapas y un reglamento de régimen jurídico.

Según el informe 7/1989 de la Secretaría General del Consell Comarcal, de 30 de octubre de 1989, el Programa d'Actuació Comarcal ha de tener una triple naturaleza: instrumento de planificación de la actividad de la comarca, instrumento de coordinación de los servicios municipales de los Ayuntamientos comarcales entre sí e instrumento de carácter normativo.

Los Programas d'Actuació Comarcal parecen ser, pues, el instrumento marco que puede definir servicios susceptibles de delegación o convenio entre la comarca y los municipios, así como establecer las vías de actuación prioritarias para la prestación de servicios.

- El 17 de noviembre de 1989 se firmó en la sede del Ministerio de Obras Públicas y Urbanismo un convenio entre dicho Ministerio, la Generalitat de Cataluña y los Consells Comarcals del Baix Llobregat y Barcelonès para la financiación del Segundo Cinturón, entre el cual figura la llamada Pata Sur que atraviesa la comarca, enlazando en el futuro la Diagonal con el Prat.

Con la misma fecha se firmó también un convenio con la Mancomunidad de Municipios del Area Metropolitana para gestionar las expropiaciones debidas a las obras del Segundo Cinturón.

- El Pleno del Consell Comarcal aprobó el 21 de noviembre de 1989 la creación del Consell Econòmic i Social del Baix Llobregat. Primer órgano de este tipo que nace en Cataluña. En él participan sindicatos, organizaciones empresariales y el Consell Comarcal. El

(32) «La comarca ha d'elaborar i aprovar un programa d'actuació (...) en funció dels tipus de municipis $i$ de les necessitats especifiques...) 
diseño del Consell Econòmic i Social se dirige a ser un instrumento para la concertación y la negociación (33).

- Confección y edición de la revista Comarca. Apareciendo el número 1 en el mes de noviembre de 1989.

- Diversas campañas para el control de mosquitos en el delta del Llobregat: prospecciones, tratamiento larvario, tratamientos periódicos con adulticidas, etc.

- Mejoras en la adecuación del Cementerio de Roques Blanques: construcción de osarios, de tumbas, pavimentación de la zona circundante al horno incinerador, del acceso al recinto, etc.

- El 28 de diciembre de 1989 se firmó un convenio entre el Consell Comarcal y el Institut Català d'Assitència i Serveis Socials (ICASS) de la Generalitat de Cataluña, para la asunción de los servicios sociales de la red básica de atención primaria en los municipios de la comarca de menos de 20.000 habitantes.

- Proposición de ley, dirigida a la Mesa del Parlamento Autonómico, con el objeto de ampliar las competencias en materia de planificación urbanística. Proposición que fue aprobada por el Consell Comarcal el 10 de enero de 1990. Quedando en estos momentos a la espera de la resolución de la Generalitat.

- El día 16 de enero de 1990 se aprobó en sesión plenaria, a propuesta de la Comisión de Gobierno del día 27 de diciembre de 1989, el denominado «Pla de Xoc de Formació Professional Ocupacional per a la Comarca del Baix Llobregat». Dicho plan engloba diferentes programas de actuación para el fomento de la ocupación, dirigidos a jóvenes parados menores de veinticinco años, a los parados de larga duración y a promover la reinserción en el mundo del trabajo de las mujeres mayores de veinticinco años.

Dicho plan está diseñado para una duración de dos años y con un presupuesto inicial de 1.182.258.320 pesetas. La financiación del cual queda supeditado a la posible subvención del Fondo Social Europeo.

El acuerdo, en su apartado segundo, instaba a la comunicación del plan aprobado al Director General d'Ocupació del Departament de Treball de la Generalitat de Cataluña para su correspondiente tramitación.

(33) Dicho Consell se fundamentó en el desarrollo del derecho a la participación reconocido en la Ley 7/1985, Reguladora de las Bases del Régimen Local. El Consell Comarcal, y mediante los artículos 35 y 36 del Reglamento Orgánico Comarcal, estableció el Consell Econòmic i Social, como Consejo sectorial de participación de carácter permanente, con funciones consultivas respecto a los asuntos de interés comarcal, en el cual se encuentran representados los grupos políticos comarcales, asi como organizaciones empresariales y sindicales. 
El Consell Econòmic i Social, en su sesión constitutiva del día 15 de marzo de 1990, manifestó su apoyo a dicho plan de choque contra el paro en la Comarca del Baix Llobregat.

- En el mes de enero se constituyó la Ponència Tècnica Comarcal, la cual está facultada para cualificar e informar los expedientes de las actividades clasificadas, según el Reglamento de Actividades Molestas, Insalubres, Nocivas y Peligrosas, y de los cuales se haya solicitado oportuna licencia previa por los Ayuntamientos de la comarca de menos de 50.000 habitantes (34).

- La Comisión de Gobierno del Consell Comarcal aprobó el día 30 de enero de 1990 la integración del Consell Comarcal como socio fundador de la Fundación privada "Utopia d'Estudis Socials Baix Llobregat» $y$, en consecuencia, la constitución de dicha entidad.

La Comisión de Gobierno fundamentó dicho acto, desde el punto de vista jurídico, en el desarrollo del artículo $25.1, d$ ), de la Ley 6/1987, de 4 de abril, sobre Organización Comarcal de Cataluña, el cual reconoce a la comarca competencias en el campo de la cultura. Por otra parte, desarrolla también el artículo 44 de la Constitución, donde, se refiere a la acción de los poderes públicos para promover y tutelar el acceso a la tutela en aras al interés general.

Dicho acuerdo aprobó la propuesta realizada conjuntamente por los Sindicatos UGT y CC.OO.

El objetivo de constituir dicha Fundación se dirigía hacia el desarrollo de todo tipo de actividades y estudios en el campo de tos movimientos sociales, su historia y su desarrollo económico.

Dicho acuerdo aprobó también en su apartado segundo los estatutos reguladores de la Fundación, así como una aportación inicial de 360.000 a cargo del Consell Comarcal.

Tanto en las diferentes iniciativas, antes mencionadas, como de otras vigentes de las que forma parte o se adhiere el Consell Comarcal del Baix Llobregat, se observa que a lo largo de estos dos primeros años la actividad de esta administración local ha sido, si no prolífica, sí importante.

Desde el momento en que instauran las comarcas, la del Baix Llobregat, y a diferencia de otras, arranca ya con competencias transferidas. Estas, que provienen de la Corporación Metropolitana, permiten que ya desde un primer momento el aparato político $y$

(34) Según la Ley 6/1987, sobre la organización comarcal de Catalunya, la administración comarcal ejercerá competencias en materia de salubridad pública y medio ambiente. Según esto y en virtud del Decreto 364/1988, de 1 de diciembre, la Generalitat de Catalunya faculta a los Consells Comarcals para intervenir en el trámite de cualificación e informe de las actividades clasificadas en determinados supuestos. 
administrativo del Consell Comarcal se encuentra con unas competencias y servicios a gestionar. Peculiaridad ésta que actúa, a nuestro parecer, como catalizador y reactivo en la voluntad política de los representantes de la comarca.

La voluntad política del Consell Comarcal parece dirigirse, tal y como se observa en las actuaciones de las que es promotor o forma parte, a estimular el "espíritu» comarcal de los municipios que lo componen. La fórmula empleada ha sido generar acciones de carácter supramunicipal (mediante acciones para la promoción económica de la comarca), mejorar los canales de comunicación -formales e informales- con los diferentes consistorios de la comarca (subvenciones para la adquisición de telefax) o actuar como máximo representante de representantes de la comarca (firma en el Ministerio de Obras Públicas y Urbanismo del convenio de financiación del Segundo Cinturón).

\section{A MODO DE CONCLUSION}

La Ley 6/1987 es el punto de partida jurídico para cualquier reflexión actual sobre las comarcas. Ahora bien, ¿cómo se materializa, desde el punto de vista real, esa voluntad del legislador autónomo más allá de su aspecto jurídico? Como hemos indicado a lo largo de las anteriores reflexiones, ni la financiación de las comarcas ni el ámbito competencial de las mismas parece permitir, en los momentos actuales, niveles de autonomía financiera, ni tan siquiera tener un marco definido de actuación.

La financiación y las competencias no son los dos únicos handicaps con los que parten las comarcas. Otro reto es, sin duda, que los Consells Comarcals sean aceptados por los municipios que la componen. Esta legitimidad, necesaria para un buen entendimiento y desarrollo del modelo comarcal, ha de encontrar su sino, más allá de la esencia histórica, en virtud de su eficacia operativa. El hecho de una representatividad política parcial, por ser de segundo grado, puede jugar en su contra, al menos en unos primeros momentos. Parece ser que, en último extremo, corresponde a los distintos consistorios otorgar a la representación comarcal «carta de naturaleza». El equilibrio parece difícil. Pues se trata de ofrecer un apoyo al municipio y un respeto a su autonomía.

Otro reto de la organización comarcal son las relaciones intergubernamentales, confusas hasta ahora con las Diputaciones de Barcelona y conflictivas, en algunos momentos, con el Gobierno de la Generalitat. La necesidad de aclarar el marco de actuación comarcal con estos niveles de gobierno encuentra su justificación 
tanto en la necesidad de evitar duplicidades de servicios como en la mejora de la eficacia y eficiencia administrativa.

El Consell Comarcal del Baix Llobregat, como indicábamos anteriormente, es un Consell Comarcal atípico desde sus inicios. Heredó diversos servicios de la estinta Corporación Metropolitana. Hecho éste que permitió que, tanto la maquinaria política como la administrativa, empezase a funcionar, a niveles comarcales, más precozmente que en otros casos. Esto, que inicialmente era una ventaja para desarrollar el modelo comarcal, tenía el problema de la financiación de los servicios heredados. Como sabemos, las comarcas, así como las áreas metropolitanas, las provincias o las mancomunidades de municipios, carecen de imposiciones tributarias propias. Este hecho, junto con los problemas de financiación a través del Fondo de Cooperación Local de Cataluña, hace que el Consell Comarcal del Baix Llobregat carezca de una plena autonomía financiera.

Tampoco podemos obviar el nivel competencial. Ya hemos referido en anteriores apartados la dificultad competencial con la que actúa el Consell Comarcal. El escasamente definido marco competencial no resulta tampoco una ventaja para ningún nivel de gobierno, y menos aún para los ciudadanos. Las competencias provenientes de la Generalitat o de las Diputaciones están previstas, en su fórmula original, que se desarrollen mediante leyes sectoriales o por vía de convenios. Ambas vías, escasamente desarrolladas, como hemos visto anteriormente.

Con todos estos problemas, podríamos pensar ¿cuál ha sido en realidad la actuación del Consell Comarcal del Baix Llobregat en sus dos primeros años de funcionamiento? Desde sus inicios, la actuación ha sido, por los problemas anteriormente indicados, actuaciones, en la mayor parte de los casos, bajo mínimos y, en la mayoría de ellos, con dificultades financieras. Aun así, la voluntad de acción política ha tenido carácter de fuerte continuidad.

Hasta antes del asentamiento definitivo en el Parc de Torreblanca, el Consell Comarcal venía celebrando sus plenarios en distintos consistorios de sus municipios, sobre todo en el Ayuntamiento de Sant Feliu. Desde allí, y con carácter de uprovisionalidad", se acordaban las diferentes actuaciones comarcales.

Con la promulgación definitiva del Reglamento Orgánico del Consell Comarcal del Baix Llobregat, en junio de 1989, se dota esta comarca de su regulación marco para el régimen organizativo y de funcionamiento de los servicios comarcales.

Podíamos decir que los esfuerzos iniciales de este Consell se han dirigido a crear un "corpus» reglamentario y organizativo que defina, en un marco de referencia básico, la estructura orgánica y 
reglamentaria de la acción comarcal. Paralelamente a esta voluntad autoorganizativa, las acciones promovidas desde el Consell Comarcal se han dirigido hacia dos frentes diferenciados, pero complementarios a la vez: un frente exterior $y$ otro interior.

El primero es el que se refiere a los acuerdos, convenios o negociaciones de toda índole con el Gobierno de la Generalitat o con sus representantes directos. Este frente de actuación ha sido el que, en los primeros momentos, ha precisado mayores esfuerzos. La necesidad de dotarse tanto de fuentes de financiación, de competencias, así como participar en la mesa de negociación de distintos convenios o acuerdos así lo requería. En esta línea de actuación exterior también se incluyen las relaciones con la Diputación de Barcelona (informales en la mayoría de los casos) o con el Estado central (por ejemplo, con el Ministerio de Obras Públicas y Urbanismo en el tema del Segundo Cinturón). En ambos casos, de menor importancia que con el Gobierno autónomo.

Con el frente unterior» nos referimos a las relaciones con los municipios de la comarca. Si en el primer caso el objetivo final era obtener niveles de autonomía decisoria, en este segundo caso el objetivo es obtener niveles de legitimación frente a los municipios y sus consistorios. Las líneas de actuación se han dirigido, en este segundo caso, tanto a mejorar los canales de comunicación con los municipios como a diferentes acciones de tipo supramunicipal.

Es difícil opinar sobre cuál es el actual nivel de legitimidad que tienen los Consells Comarcals. De cualquier manera y por lo que respecta al Consell Comarcal del Baix Llobregat, parece existir voluntad política para desarrollar este nuevo nivel de gobierno. Las diferentes acciones de gobierno así lo demuestran. Las dificultades son actualmente muchas. Tanto por los problemas de tipo financiero y competencial como por los escasos recursos con los que cuenta, recursos que en último extremo son los que pueden ayudar a legitimar su acción frente a los municipios.

En resumen y en cualquiera de los casos, el modelo comarcal es un modelo no concluido. Su estado actualmente embrionario no permite un análisis en profundidad de esta nueva administración local. El reto de que llegue a arraigar en el tejido social en el que está inserto es tanto de los responsables políticos como de la población en general, que es, en último extremo, hacia la que se dirigen las acciones de cariz comarcal. Reto que sólo podrá ser evaluado cuando las comarcas cuenten con mayores niveles de autonomía que les permitan actuar más allá de los corsés institucionales de los que están insertos actualmente. 